\title{
"Ten commandments" for the appropriate use of antibiotics by the practicing physician in an outpatient setting
}

\section{Gabriel Levy-Hara ${ }^{1}$, Carlos F Amábile-Cuevas ${ }^{2}{ }^{*}$, lan Gould ${ }^{3}$, Jim Hutchinson ${ }^{4}$, Lilian Abbo ${ }^{5}$, Lynora Saxynger ${ }^{6}$, Erika Vlieghe ${ }^{7}$, Fernando L. Lopes Cardoso ${ }^{8}$, Shaheen Methar ${ }^{9}$, Souha Kanj ${ }^{10}$, Norio Ohmagari ${ }^{11}$, Stephan Harbarth ${ }^{12}$ and on behalf of the International Society of Chemotherapy Antimicrobial Stewardship Working Group ${ }^{\dagger}$}

' Division of Infectious Diseases, Hospital Carlos Durand, University of Buenos Aires, Buenos Aires, Argentina

2 Fundación Lusara, Mexico City, Mexico

${ }^{3}$ Medical Microbiology, Aberdeen Royal Infirmary, Foresterhill, Aberdeen, UK

${ }^{4}$ Division of Medical Microbiology, Island Medical Program, University of British Columbia, Victoria, BC, Canada

${ }^{5}$ Division of Infectious Diseases, Jackson Memorial Hospital, University of Miami, Coral Gables, FL, USA

${ }^{6}$ Division of Infectious Diseases, University of Alberta, Edmonton, AB, Canada

7 Department of Clinical Sciences, Institute of Tropical Medicine, Antwerp, Belgium

${ }^{8}$ Infectious Diseases and Hospital Infection Control, Hospital Universitário Clementino Fraga Filho, Universidade Federal do Rio de Janeiro, Rio de Janeiro, Brazil

${ }^{9}$ Unit for Infection Prevention and Control, Tygerberg Hospital and Faculty of Health Sciences, Stellenbosch University, Cape Town, South Africa

${ }^{10}$ Division of Infectious Diseases and Infection Control Program, American University of Beirut Medical Center, Beirut, Lebanon

"Division of Infectious Diseases, Shizuoka Cancer Center Hospital, Shizuoka, Japan

12 Service Prévention et Contrôle de I'Infection, Hôpitaux Universitaires de Genève, Genève, Switzerland

\section{Edited by:}

Tzi Bun Ng, The Chinese University of Hong Kong, China

\section{Reviewed by:}

Mamie Hui, The Chinese University of Hong Kong, China

\section{${ }^{*}$ Correspondence:}

Carlos F. Amábile-Cuevas, Fundación

Lusara, Apartado Postal 8-895, 08231 ,

Mexico City, Mexico.

e-mail:carlos.amabile@/usara.org

${ }^{t}$ The International Society of

Chemotherapy Antimicrobial Stewardship Working Group: Alex Aiken (Nairobi, Kenya), Amani Alnimr (Al Khobar, Saudi Arabia), Luis

Bavestrello (Valparaíso, Chile), Jean Carlet (Creteil, France), Anahi Dreser (Cuernavaca, México), Sabiha Essack (Durban, South Africa), Po-Ren Hsueh (Taipei, Taiwan), Nadia Ismail (Al Khobar, Saudi Arabia), Deogratias Kaddu-Mulindwa (Adelaide, Uganda), Hans Jørn Kolmos (Odense,

Danmark), Takahiro Mochizuki

(Shizuoka, Japan), Linus Ndewga (Nairobi, Kenya), Carla Odio (San José, Costa Rica), Miguel Angel Peredo (México DF, México), Silvio Vega (Panamá, Panamá), Rajlakshmi Viswanathan (Kolkata, India), Heiman Wertheim (Hanoi, Viet Nam).
A multi-national working group on antibiotic stewardship, from the International Society of Chemotherapy, put together ten recommendations to physicians prescribing antibiotics to outpatients. These recommendations are: (1) use antibiotics only when needed; teach the patient how to manage symptoms of non-bacterial infections; (2) select the adequate ATB; precise targeting is better than shotgun therapy; (3) consider pharmacokinetics and pharmacodynamics when selecting an ATB; use the shortest ATB course that has proven clinical efficacy; (4) encourage patients' compliance; (5) use antibiotic combinations only in specific situations; (6) avoid low quality and sub-standard drugs; prevent prescription changes at the drugstore; (7) discourage self-prescription; (8) follow only evidence-based guidelines; beware those sponsored by drug companies; (9) rely (rationally) upon the clinical microbiology lab; and (10) prescribe ATB empirically - but intelligently; know local susceptibility trends, and also surveillance limitations.

Keywords: antibiotic stewardship, antibiotic resistance, guidelines, generic antibiotics, self-prescription, treatment compliance

\section{INTRODUCTION}

Appropriate use of antimicrobials is defined by the WHO as "the cost-effective use of antimicrobials which maximizes clinical therapeutic effect while minimizing both drug-related toxicity and the development of antimicrobial resistance" (WHO Department of Communicable Disease Surveillance and Response, 2001).
Antimicrobial resistance is one of the most urgent health threats people are facing all around the world.

The Antimicrobial Stewardship Working Group of the International Society of Chemotherapy was established in 2009, with the aim of promoting a judicious use of antimicrobials by fostering collaboration on a global scale. Nowadays, the five continents are 
represented in our group, and experts from all of them have participated in the creation and discussion of these 10 tips and top action items for the practicing physician in an outpatient setting. These recommendations aim to guide physicians who prescribe antibiotics (ATB) to do so with caution, in order to maintain the usefulness of these pivotal therapeutic tools.

The members of the working group understand that there are many other factors that strongly cause the misuse of ATB, such as their use in agroindustry and veterinary practice (at least half of the worldwide production), the deficient medical education regarding antimicrobial stewardship, the poor or non-existent control of ATB production, marketing, and promotion, the lack of community-oriented information on ATB use, and a weak regulation of drugstores that triggers self-prescription, among others. However, we are convinced that if the following simple action items are widely known and applied, it would greatly contribute to improve antimicrobial usage. The present document summarizes our recommendations to improve the use of ATB in outpatient settings.

\section{USE ANTIBIOTICS ONLY WHEN NEEDED; TEACH THE PATIENT HOW TO MANAGE SYMPTOMS OF NON-BACTERIAL INFECTIONS}

Studies worldwide show that at least half of prescribed ATB are not necessary or otherwise abused (Gonzales et al., 2001; Akkerman et al., 2004; Castro et al., 2008; Dryden et al., 2009). Therefore, despite the obvious nature of this recommendation, physicians need to embrace this notion. For instance, ATB are often prescribed against viral infections: $50-80 \%$ of patients displaying viral symptoms receive ATB (Linder and Stafford, 2001; Castro et al., 2008; NIHCE, 2008; Vergison et al., 2010). A particular case is pharyngitis, where at least $80 \%$ of the cases have a viral etiology (Cooper et al., 2001; Bisno et al., 2002), and there are clear criteria to assess when and how to treat (Centor et al., 2007). The very need for using ATB against streptococcal pharyngitis in countries where rheumatic fever is not a problem, is controversial (Del Mar et al., 2006; NIHCE, 2008). Otitis media (in children without high fever or vomiting) (Little et al., 2001a,b; Spurling et al., 2007) is another example where ATB are abused; the patient (or the patient's parents) would benefit from a brief explanation of supportive measures (anti-pyretics, baths, hydration, etc.), the neglectable outcome difference with or without ATB, and the very common adverse reactions, such as diarrhea or rash, that might outweigh the benefit of using ATB in upper respiratory tract infections (Linder, 2008; Coker et al., 2010). Spending a few minutes educating our patients so that they understand the impact of antibiotic abuse, might prevent them to seek a colleague willing to prescribe ATB. Other situations where ATB may not be needed include: (a) fever without other signs and symptoms of infection; (b) self-limiting bacterial infections, such as many diarrheal diseases (Chiu et al., 1999; Sirinavin and Garner, 2000); (c) asymptomatic bacteriuria, except during pregnancy (Tambyah and Maki, 2000; Nicolle et al., 2005); and (d) asymptomatic colonization of skin ulcers, sores, and wounds. The role of ATB in the management of exacerbations of chronic bronchitis (Puhan et al., 2007), fever and minor infections in immunosuppressed patients, and atypical community-acquired pneumonia (CAP) in outpatients (Mills et al., 2005; Shefet et al., 2005), is also controversial. A review of ATB use and abuse has been recently published (Leekha et al., 2011).

\section{SELECT THE ADEQUATE ATB; PRECISE TARGETING IS BETTER THAN SHOTGUN THERAPY}

This should be another obvious recommendation, but prescriptions of aminoglycosides for CAP or ceftriaxone for urinary tract infections (UTI), for instance, are so common, that this is clearly an issue. Physicians must know the prevalent pathogens for each kind of infection, and the local susceptibility trends (also, ideally, the local prevalence of resistance mechanisms). Despite the many different bacteria that cause infections in humans, in the outpatient setting there is only a handful of relevant organisms: Streptococcus pneumoniae, S. pyogenes, and Haemophilus influenzae causes most bacterial respiratory infections; uropathogenic Escherichia coli, Proteus mirabilis, and Klebsiella pneumoniae causes most UTI; enteropathogenic E. coli, Salmonella spp., and Shigella spp. causes most enteral infections; Staphylococcus aureus and S. pyogenes causes skin and soft-tissue infections; Neisseria gonorrhoeae is the most relevant sexually transmitted pathogen; $H$. influenzae and N. meningitidis causes bacterial meningitis. Susceptibility trends of these pathogens (see recommendation number 10) should be available in a local, timely fashion, so that they can guide empirical therapy.

Narrow spectrum drugs should be preferred when possible: wide-spectrum is only necessary when potential causative pathogens are very diverse, or when the infection is potentially polymicrobial. Wide-spectrum aminoglycosides are a bad choice against pneumococcal infections (hence, not adequate for nearly half lower respiratory tract infections), and third-generation cephalosporins are excessive for most cases of otitis media or UTI (in fact, plain amoxicillin is usually enough, instead of "using a cannon to shoot a fly"). Once a drug class has been selected, it is important to avoid using those more likely to select for resistance, such as long-half-life macrolides (Baquero, 1999), or low-potency fluoroquinolones (Credito et al., 2010).

\section{CONSIDER PHARMACOKINETICS AND PHARMACODYNAMICS WHEN SELECTING AN ATB; USE THE SHORTEST ATB COURSE THAT HAS PROVEN CLINICAL EFFICACY}

Most dosage indications for ATB are decades old, when data on $\mathrm{PK}, \mathrm{PD}$, and resistance was still emerging. In some cases, changes have been made, such as the evolution of aminoglycoside dosing, from three times per day to only once; but many deficiencies are still hidden in standard treatment schemes. Physicians must review available data on $\mathrm{PK} / \mathrm{PD}$ in order to adequately select drugs and dosing, and to prevent resistance (Li and Tang, 2005; Craig and Slauch, 2009; Mazzei et al., 2009; Leekha et al., 2011). Drugs belonging to the same family may significantly differ, so that they are not exchangeable.

Starting in the early 1980s, ATB can be classified as concentration- or time-dependent; aminoglycosides, fluoroquinolones, colistin and metronidazole are concentrationdependent, while beta-lactams and most macrolides are timedependent (Craig, 2001). This classification is useful in designing 
rational dosing schemes, but this information often arrived after prescribing information was written. Also, ATB are almost always used in adults in fixed doses, unlike the common adjustments made by pediatricians. It is unlikely that a patient of $1.50 \mathrm{~m}$ and $45 \mathrm{~kg}$ would need the same dose as another of $1.90 \mathrm{~m}$ and $110 \mathrm{~kg}$; perhaps ATB dosing must now be adjusted for weight (Falagas and Karageorgopoulos, 2010), to avoid prescribing too little or too much of a drug. The global increase in human weight has forced to recalculate the average weight of passengers in airplanes and ships, but this recalculation is still missing in drug dosing.

The length of ATB treatments was also developed when the main concern was efficacy and safety - but not resistance. Hence, treatments were unnecessarily long. There are not enough clinical trials designed to measure the efficacy of shorter courses, but well-done studies have demonstrated it for UTI (ArredondoGarcía et al., 2004; Vogel et al., 2004; Kyriakidou et al., 2008; Lutters and Vogt-Ferrier, 2008), acute otitis media (Kozyrskyj et al., 2010), acute exacerbations of chronic bronchitis (El Moussaoui et al., 2008; Falagas et al., 2008), acute streptococcal pharyngitis (Altamimi et al., 2009), and acute sinusitis (Falagas et al., 2009). In contrast, there is no supporting evidence for many of the traditional 10-14 day ATB courses, which are based more on conventional wisdom or expert opinion (Mouton et al., 2011). Although there are many factors to be considered (infection site, involved pathogen, tissue concentration and PD of ATB, etc.) short courses have comparable efficacy with less exposure, less side effects, less risk of resistance development and less cost. In brief: shorter is better (Harbarth et al., 2000; D’Agata et al., 2007; Mouton et al., 2011). Therefore, whenever available, physicians must rely on published information, and shorten treatments if possible; physicians' resistance to shorten treatments will only foster bacterial resistance to ATB.

\section{ENCOURAGE PATIENTS' COMPLIANCE}

The best ATB would fail if the patient does not comply with the treatment. Compliance (i.e., taking the indicated doses at the indicated time periods, and completing treatment as prescribed) is in average only around 50\%; there are many strategies that the physician can use to improve patients' compliance (Buxton, 2006). Communication is key in this regard: physicians must ensure that the patient understood the prescription, assist him/her in scheduling doses according to their activities, suggest when possible the use of devices, from pill casings for hours or days, to the use of PDAs or cell phones with programmable alarms. Drugs that require only one or two doses per day usually have better compliance rates; injectable ATB, on the other side, are associated to premature discontinuation of treatments (and, with the exception of benzylpenicillin, are often completely unnecessary in the outpatient setting). Lack of compliance can potentially lead to resistance, due to repeated exposure to sub-inhibitory concentrations of ATB, that foster the emergence of resistance (Cebrián et al., 2006; Henderson-Begg et al., 2006; Linares et al., 2006; Cortes et al., 2008). Patients' understanding of this risk, as well as its health and economic consequences to him/her, and to his/her relatives is a responsibility that physicians must take the moment they prescribe an ATB.

\section{USE ANTIBIOTIC COMBINATIONS ONLY IN SPECIFIC SITUATIONS}

Combinations of antibiotics increase the exposure of bacteria to these drugs, which select resistance, increase the costs and have more chance of being accompanied by side effects resulting from drug interactions. For community-acquired infections, the best drug for the job is usually a single one. Notable exceptions include, of course, the management of tuberculosis, where combining drugs is the best way to prevent resistance; the therapy of moderate to severe CAP of unknown etiology, that may include pneumococci (usually susceptible to beta-lactams, but growingly resistant to macrolides) or "atypical" bacteria (intrinsically resistant to beta-lactams, but susceptible to macrolides) can be treated with combinations of beta-lactams and macrolides before resorting to fluoroquinolones (Miyashita et al., 2006; Mandell et al., 2007; Menéndez et al., 2010). Management of Helicobacter pylori infections also require ATB combinations. The emerging threat of community-acquired methicillin-resistant $S$. aureus (CA-MRSA) causing skin infections, can often be faced by adding sulfamethoxazole-trimethoprim or clindamycin, to the beta-lactam usually prescribed for this kind of diseases (Ruhe et al., 2007; Levy Hara et al., 2009). However, combinations lacking supporting evidence, that many physicians use "just in case," should be avoided.

\section{AVOID LOW OUALITY AND SUB-STANDARD DRUGS; PREVENT PRESCRIPTION CHANGES AT THE DRUGSTORE}

Terms "low quality" and "sub-standard" are used here to refer to generic drugs that do not meet the requirements of bioequivalence $(98-102 \%$ of active ingredient as labeled, $85-125 \%$ of maximum plasma concentration, $C_{\max }$, and time-concentration area under the curve, AUC, of the original drug). Unfortunately, even those minimal requirements are not considered by national health authorities of many countries. Bioequivalence is not necessarily a test for clinical efficacy (Vesga et al., 2010); furthermore, lack of quality control, corruption, counterfeit drugs, deficient control at drugstores, etc. (Newton et al., 2010), common in developing countries, diminish the confidence on generic drugs. Additionally, even in developed countries, generic drugs are sub-standard (Del Tacca et al., 2009). Low quality ATB may result in pharmacokinetic profiles much different from the ones of original drugs which, in turn, may create increased periods of time of sub-inhibitory concentration exposure, leading to treatment failure and/or resistance. This is not, of course, a problem plaguing all generic drugs; many products have shown to be bioequivalent to original ones (Mazur et al., 1999; Galan-Herrera et al., 2009). But the "burden of evidence" should rely on generic manufacturers, which should demonstrate clinical efficacy instead of only bioequivalence. In many countries it is also a common practice from drugstore salespeople to change physicians' prescriptions. Physicians must alert patients of this practice, which is also a risk for a complete change of drug or modified-release formulation. (The working group that developed these recommendations is aware that this one is controversial and, in many developing countries, unaffordable; however, we urge the reader to consider it, within the local market and financial features). 


\section{DISCOURAGE SELF-PRESCRIPTION}

Self-prescription, or otherwise non-medical prescription (which includes the advice of relatives, friends or drugstore salespeople) is not the main cause of antibiotic abuse in most countries, and is not corrected only by requiring prescriptions to buy antibiotics. However, the use of ATB in these uncontrolled and often unnecessary conditions is high in developing countries, ranging from 20 to 40\% (Drug Utilization Research Group, 1997; Amábile-Cuevas et al., 1998; Gaur and English, 2006; Grigoryan et al., 2010). From the physician's point of view, communication with patients is again pivotal to prevent self-prescription: discussing, in lay terms, the consequences of antibiotic abuse and its impact on their health and economy, must go along with ATB prescription. Promoting compliance (see recommendation number 4) also reduces a common source of self-prescription: the use of ATB leftovers, often inadequate and expired. If communication with local pharmacists is possible, physicians must stress the societal risk that ATB self-prescription poses, so that this practice is minimized.

\section{FOLLOW ONLY EVIDENCE-BASED GUIDELINES; BEWARE THOSE SPONSORED BY DRUG COMPANIES}

Therapeutic guidelines have recently become the basis of therapeutic choices. Realizing this trend, pharmaceutical companies often sponsor all sorts of guidelines and recommendations, pushing for the inclusion of newer, more expensive treatment options, but lacking experimental evidence of their superiority upon older and cheaper drugs. Some medical journals also join this trend by allowing such biased recommendations to be published, commonly as supplements (Rochon et al., 1994). It is crucial to look for guidelines based on systematic reviews of available literature, describing levels of evidence, instead of those merely stating "expert opinions" (Hippocrates once said: "There are in fact two things, science and opinion; the former begets knowledge, the latter ignorance"). It is unfortunately common to find guidelines developed by specialists' societies or groups, recommending the use of more expensive ATB in the absence of evidence of superiority over cheaper options; the levels of evidence to sustain such recommendations are often not consistent with the literature.

Aside, it can also be argued that even the best treatment guidelines are only focused on efficacy and safety, but miss the societal side of ATB, i.e., the resistance promotion side. Furthermore, some mathematical models predict that the use of guidelines encourage the intensive use of just some drugs, which rapidly select for resistance (Laxminarayan and Weitzman, 2003). It is important to encourage the inclusion of resistance analyses in therapeutic guidelines, aside of efficacy and safety concerns. Finally, if medicine were purely a matter of guidelines, an appropriate software may easily replace the physician; guidelines universalize individual problems, and make us face them with a very limited range of options.

\section{RELY (RATIONALLY) UPON THE CLINICAL MICROBIOLOGY LAB}

The microbiology laboratory can provide significant support in some cases of infection, although in most cases it is only used when a first ATB empirically prescribed has failed. By performing cultures for the diagnosis of prevalent infections (UTI, diarrhea) the patient can be treated in an adequate and safe way. However, the lab cannot provide reliable answers in some cases, such as lower respiratory tract infections, where the etiology can be assessed in no more than half of the cases. On the other hand, the lab input is unnecessary, as when trying to know the etiology of pharyngitis (or the susceptibility of $S$. pyogenes to beta-lactams). Physicians must be familiar with the laboratory their patients are referred to: it should have well-documented quality controls, reference strains, etc., so that it provide reliable results. This is particularly necessary in countries where clinical labs run without major supervision from health authorities. It is also crucial to know how to collect a useful sample, and what are the limitations of each analysis (e.g., a nasal swab is not adequate for assessing the etiology of sinusitis; and standard susceptibility testing cannot consider many pharmacokinetic and PD factors that affect clinical efficacy). By choosing a good lab, and using it only when the information it would provide is really meaningful, patients will save money and antibiotic prescription will improve.

\section{PRESCRIBE ATB EMPIRICALLY -BUT INTELLIGENTLY; KNOW LOCAL SUSCEPTIBILITY TRENDS, AND ALSO SURVEILLANCE LIMITATIONS}

The need for surveillance of resistance has been highlighted many times (German et al., 2001; WHO Department of Communicable Disease Surveillance and Response, 2001; O'Brien and Stelling, 2007), but there are limited efforts to monitor resistance globally. Developing countries often lack reliable surveillance programs, especially of community-acquired pathogens (Tenover et al., 2001; Chaitram et al., 2003); data in developed countries is of better quality (Bronzwaer et al., 2002), and can even be linked to usage patterns. However, the amount of susceptibility data is overwhelming: local and international meetings of infectious diseases societies are full of posters and symposia on it. Many of these data are generated by projects sponsored by pharmaceutical companies, hence it is important to read them carefully. Simple contradictions may reveal bias or plain wrongdoing: if two fluoroquinolones perform significantly different against $E$. coli isolates, or if the prevalence of MRSA is very different from the resistance prevalence toward amoxicillin-clavulanate, or if a set of pneumococci are highly resistant to fluoroquinolones but very sensitive to macrolides, we must suspect the quality and/or transparency of these results. Furthermore, many susceptibility surveillance projects are inherently biased; researchers rely on isolates from clinical labs, but physicians only send patients to the lab when facing complications or initial failure of empirically prescribed drugs. Resistance prevalence data may therefore be overestimated (Lopardo et al., 2007), precluding the use of ATB that might actually work.

\section{FINAL CONSIDERATIONS}

Tips that can be singled out: avoid ATB for bronchitis when pneumonia is not a concern; avoid ATB for watery diarrhea when dysentery of typhoid fever is not a concern; delay the use of ATB against otitis media for at least $48 \mathrm{~h}$; consider nitrofurantoin instead of fluoroquinolones against uncomplicated cystitis; reserve respiratory fluoroquinolones for unresponsive or highrisk CAP patients; and avoid fixed-dose combinations of ATB and anti-inflammatory or anti-histaminic drugs. 
Preventing bacterial diseases is a much better way to avoid the use of ATB and all of its consequences. Vaccines reduce disease prevalence and ATB demand. Immunizations against influenza, pneumococci, $H$. influenzae $\mathrm{B}$, meningococci, and Salmonella Typhi can have a pivotal role in reducing the need for ATB.

Pharmaceutical companies provide us with great drugs and continuously invest in research and development; but the marketing side is only aimed at promoting the use of their products including, of course, ATB. Through many strategies, pharmaceutical companies strongly influences prescribing behaviors, in ways not necessarily supported by the best evidence; papers sponsored by big pharma are often biased (Chren and Landefeld, 1994; Rochon et al., 1994; Levy Hara et al., 2006; Anderson et al., 2009). Of course, this does not

\section{REFERENCES}

Akkerman, A. E., Van Der Wouden, J. C., Kuyvenhoven, M. M., Dielemar, J. P., and Verheij, T. J. (2004). Antibiotic prescribing for respiratory tract infections in Dutch primary care in relation to patient age and clinical entities. J. Antimicrob. Chemother. 54, 1116-1121.

Altamimi, S., Khalil, A., Khalaiwi, K. A., Milner, R., Pusic, M. V., and Al Othman, M. A. (2009). Short versus standard duration antibiotic therapy for acute streptococcal pharyngitis in children. Cochrane Database Syst. Rev. 1, CD004872.

Amábile-Cuevas, C. F., Cabrera, R., Fuchs, L. Y., and Valenzuela, F. (1998). Antibiotic resistance and prescription practices in developing countries. Methods Microbiol. 27, 587-594.

Anderson, B. L., Silverman, G. K., Loewenstein, G. F., Zinberg, S., and Schulkin, J. (2009). Factors associated with physicians' reliance on pharmaceutical sales representatives. Acad. Med. 84, 994-1002.

Arredondo-García, J. L., FigueroaDamián, R., Rosas, A., Jáuregui, A., Corral, M., Costa, A., Merlos, R. M., Ríos-Fabra, A., AmábileCuevas, C. F., Hernández-Oliva, G., Olgín, J., Cardeñosa-Guerra, O., and uUTI Latin American Study Group. (2004). Comparison of short-term treatment regimen of ciprofloxacin versus long-term treatment regimens of trimethoprim/sulfamethoxazole of norfloxacin for uncomplicated lower urinary tract infections: a randomized, multicentre, open-label, prospective study. J. Antimicrob. Chemother. 54, 840-843.

Baquero, F. (1999). Evolving resistance patterns of Streptococcus pneumoniae: a link with longacting macrolide consumption? J. Chemother. 11(Suppl. 1), 35-43.
Bisno, A., Gerber, M., Gwaltney, J. M., Kaplan, E., and Schwartz, R. (2002). Practice guidelines for the diagnosis and management of group A streptococcal pharyngitis. Clin. Infect. Dis. 35, 113-125.

Bronzwaer, S., Buchholz, U., Courvalin, P., Snell, J., Cornaglia, G., De Neeling, A., Aubry-Damon, H., Degener, J., and EARSS participants. (2002). Comparability of antimicrobial susceptibility test results from 22 European countries and Israel: an external quality assurance exercise of the European Antimicrobial Resistance Surveillance System (EARSS) in collaboration with the United Kingdom National External Quality Assurance Scheme (UK NEQAS). J. Antimicrob. Chemother. 50, 953-964.

Buxton, I. L. O. (2006). "Principles of prescription order writing and patient compliance," in The Pharmacological Basis of Therapeutics, 11th Edn, eds L. L. Brunton, J. S. Lazo, and K. L. Parker (New York: McGrawHill), 1777-1786.

Carlet, J., Collignon, P., Goldmann, D., Goossens, H., Gyssens, I. C., Harbarth, S., Jarlier, V., Levy, S. B., N'doye, B., Pittet, D., Richtmann, R., Seto, W. H., Van Der Meer, J. W., and Voss, A. (2011). Society's failure to protect a precious resource: antibiotics. Lancet 378, 369-371.

Castro, J. L., Levy Hara, G., Muñoz, S., Silveira De Castro, M., Berrios, M. E., Montenegro, A., Seaman, I., and Nazar, G. (2008). Consumo de antibióticos en Nicaragua y Honduras. Análisis de aspectos metodológicos y principales resultados. Rev. Panam. Infectol. 10(Suppl. 1), S104-S111.

Cebrián, L., Rodríguez, J. C., Escribano, I., Ruiz, M., and Royo, G. (2006). Decrease in bactericidal activity of ciprofloxacin in Salmonella mutants generated following

only affects ATB prescription, but due again to the societal nature of ATB effects, the trend, as well as the lack of adequate regulation in many countries, makes it particularly dangerous in terms of public health. Physicians must keep this in mind.

ATB are limited, non-renewable resources (Carlet et al., 2011), that we all need during our lives. "Every antibiotic expected by a patient, every unnecessary prescription written by a doctor, every uncompleted course of antibiotics, and every inappropriate or unnecessary use in animals or agriculture is potentially signing a death warrant for a future patient" (Dryden et al., 2009). We should not wait for governments to implement measures that regulate drug promotion and usage, and enforce ethical codes. Change must start with us all.

repeated exposure to various fluorquinolones. Rev. Esp. Quimioter. 19, 363-366.

Centor, R. M., Allison, J. J., and Cohen, S. J. (2007). Pharyngitis management: defining the controversy. J. Gen. Intern. Med. 22, 127-130.

Chaitram, J. M., Jevitt, L. A., Lary, S., Tenover, F. C., and WHO Antimicrobial Resistance Group. (2003). The World Health Organization's External Quality Assurance System Proficiency Testing Program has improved the accuracy of antimicrobial susceptibility testing and reporting among participating laboratories using NCCLS methods. J. Clin. Microbiol. 41, 2372-2377.

Chiu, C. H., Lin, T. Y., and Ou, J. T. (1999). A clinical trial comparing oral azithromycin, cefixime and no antibiotics in the treatment of acute uncomplicated Salmonella enteritis in children. J. Paediatr. Child Health 35, 372-274.

Chren, M. M., and Landefeld, C. S. (1994). Physicians' behavior and their interactions with drug companies. A controlled study of physicians who requested additions to a hospital drug formulary. JAMA 271, 684-689.

Coker, T. R., Chan, L. S., Newberry, S. J., Limbos, M. A., Suttorp, M. J., Shekelle, P. G., and Takata, G. S. (2010). Diagnosis, microbial epidemiology, and antibiotic treatment of acute otitis media in children. JAMA 304, 2161-2169.

Cooper, R. J., Hoffman, J. R., and Bartlett, J. G. (2001). Principles of appropriate antibiotic use for acute pharyngitis in adults. Ann. Intern. Med. 134, 509-517.

Cortes, P. R., Piñas, G. E., Albarracin Orio, A. G., and Echenique, J. R. (2008). Subinhibitory concentrations of penicillin increase the mutation rate to optochin resistance in
Streptococcus pneumoniae. J. Antimicrob. Chemother. 62, 973-977.

Craig, M., and Slauch, J. M. (2009). Phagocytic superoxide specifically damages an extracytoplasmic target to inhibit or kill Salmonella. PLoS ONE 4, e4975. doi:10.1371/journal.pone.0004975

Craig, W. A. (2001). "Pharmacodynamics of antimicrobials: general concepts and applications," in Antimicrobial Pharmacodynamics in Theory and Clinical Practice, eds C. H. Nightingale, T. Murakawa, and P. G. Ambrose (New York: Marcel Dekker), 1-22.

Credito, K., Kosowska-Shick, K., Mcghee, P., Pankuch, G. A., and Appelbaum, P. C. (2010). Comparative study of the mutant prevention concentrations of moxifloxacin, levofloxacin, and gemifloxacin against pneumococci. Antimicrob. Agents Chemother. 54, 673-677.

D’Agata, E. M., Magal, P., Olivier, D., Ruan, S., and Webb, G. F. (2007). Modeling antibiotic resistance in hospitals: the impact of minimizing treatment duration. J. Theor. Biol. 249, 487-499.

Del Mar, C. B., Glasziou, P. P., and Spinks, A. B. (2006). Antibiotics for sore throat. Cochrane Database Syst. Rev. 4, CD000023.

Del Tacca, M., Pasqualetti, G., Di Paolo, A., Virdis, A., Massimetti, G., Gori, G., Versari, D., Taddei, S., and Blandizzi, C. (2009). Lack of pharmacokinetic bioequivalence between generic and branded amoxicillin formulations, a postmarketing clinical study on healthy volunteers. Br. J. Clin. Pharmacol. 68, 34-42.

Drug Utilization Research Group, Latin America. (1997). Multicenter study on self-medication and selfprescription in six Latin American countries. Clin. Pharmacol. Ther. 61, 488-493. 
Dryden, M. S., Cooke, J., and Davey, P. (2009). Antibiotic stewardshipmore education and regulation not more availability? J. Antimicrob. Chemother. 64, 885-888.

El Moussaoui, R., Roede, B. M., Speelman, P., Bresser, P., Prins, J. M., and Bossuyt, P. M. M. (2008). Shortcourse antibiotic treatment in acute exacerbations of chronic bronchitis and COPD: a meta-analysis of double-blind studies. Thorax 63, 415-422.

Falagas, M. E., Avgeri, S. G., Matthaiou, D. K., Dimopoulus, G., and Siempos, I. I. (2008). Short-versus longduration antimicrobial treatment for exacerbations of chronic bronchitis: a meta-analysis. J. Antimicrob. Chemother. 62, 442-450.

Falagas, M. E., and Karageorgopoulos, D. E. (2010). Adjustment of dosing of antimicrobial agents for bodyweight in adults. Lancet 375 , 248-251.

Falagas, M. E., Karageorgopoulos, D. E., Grammatikos, A. P., and Matthaiou, D. K. (2009). Effectiveness and safety of short vs. long duration of antibiotic therapy for acute bacterial sinusitis: a meta-analysis of randomized trials. Br. J. Clin. Pharmacol. 67, 161-171.

Galan-Herrera, J. F., Poo, J. L., RosalesSanchez, O., Fuentes-Fuentes, E., Cariño, L., Burke-Fraga, V., Namur, S., and Parra, M. G. (2009). Bioavailability of two oral formulations of a single dose levofloxacin $500 \mathrm{mg}$ : an open-label, randomized, two-period crossover comparison in healthy Mexican volunteers. Clin. Ther. 31, 1796-1803.

Gaur, A. H., and English, B. K. (2006). The judicious use of antibiotics an investment towards optimized health care. Indian J. Pediatr. 73, 343-350.

German, R. R., Lee, L. M., Horan, J. M., Milstein, R. L., Pertowski, C. A., Waller, M. N., and Group Centers for Disease Control and Prevention (CDC). (2001). Updated guidelines for evaluating public health surveillance systems: recommendations from the Guidelines Working Group. MMWR Recomm. Rep. 50, $1-35$.

Gonzales, R., Malone, D. C., Maselli, J. H., and Sande, M. A. (2001). Excessive antibiotic use for acute respiratory infections in the United States. Clin. Infect. Dis. 33, 757-762.

Grigoryan, L., Monnet, D. L., HaaijerRuskamp, F. M., Bonten, M. J., Lundborg, S., and Verheij, T. J. (2010). Self-medication with antibiotics in Europe: a case for action. Curr. Drug Saf. 5, 329-332.

Harbarth, S., Samore, M. H., Lichtenberg, D., and Carmeli, Y. (2000). Prolonged antibiotic prophylaxis after cardiovascular surgery and its effect on surgical site infections and antimicrobial resistance. Circulation 101, 2916-2921.

Henderson-Begg, S. K., Livermore, D. M., and Hall, L. M. (2006). Effect of subinhibitory concentrations of antibiotics on mutation frequency in Streptococcus pneumoniae. J. Antimicrob. Chemother. 57, 849-854.

Kozyrskyj, A., Klassen, T. P., Moffatt, M., and Harvey, K. (2010). Shortcourse antibiotics for acute otitis media. Cochrane Database Syst. Rev. 9, CD001095.

Kyriakidou, K. G., Rafailidis, P., Matthaiou, D. K., Athanasiou, S., and Falagas, M. E. (2008). Shortversus long-course antibiotic therapy for acute pyelonephritis in adolescents and adults: a metaanalysis of randomized controlled trials. Clin. Ther. 30, 1859-1868.

Laxminarayan, R., and Weitzman, M. L. (2003). "Value of treatment heterogeneity for infectious diseases," in Battling Resistance to Antibiotics and Pesticides, and Economic Approach, ed. R. Laxminarayan (Washington DC: Resources for the Future), 63-75.

Leekha, S., Terrell, C., and Edson, R. (2011). General principles of antimicrobial therapy. Mayo Clin. Proc. 86, 156-167.

Levy Hara, G., Lopardo, G., López Furst, M. J., Bermejo, A., Clara, L., D’atri, G. M., Desse, J., De Vedia, L., Garelli, G., Goldenstein, C. E., Jaled, M. M., Klein, M., Larrea, R. M., Paolini, J. E., Pensotti, C., Perelsztein, A. G., Pryluka, D., Scapellato, P., and Stryjewski, M. E. (2009). Consensus SADISAM-SAD-CACCV. Guidelines for the rational management of skin and soft-tissue infections -part I. Rev. Panam. Infectol. 11, 47-62.

Levy Hara, G., Mestres, N. A., and Sosa, A. (2006). "La formación médica en el postgrado: ¿ha llegado el momento de reformularla?," in Uso y abuso de los antibióticos: ¿dónde estamos y adónde queremos llegar?, eds G. Levy Hara and A. Sosa (Montevideo: Arena), 205-213.

Li, R. C., and Tang, M. C. (2005). Post-antibiotic effect induced by an antibiotic combination: influence of altered susceptibility to individual components. J. Antimicrob. Chemother. 55, 583-586.

Linares, J. F., Gustafsson, I., Baquero, F., and Martinez, J. L. (2006). Antibiotics as intermicrobial signaling agents instead of weapons. Proc. Natl. Acad. Sci. U.S.A. 103 , 19484-19489.

Linder, J. A. (2008). Antibiotics for treatment of acute respiratory tract infections: decreasing benefit, increasing risk, and the irrelevance of antimicrobial resistance. Clin. Infect. Dis. $47,744-746$.

Linder, J. A., and Stafford, R. (2001). Antibiotic treatment of adults with sore throat by community primary care physicians - a national survey, 1989-1999. JAMA 286, 1181-1186.

Little, P., Gould, C., Moore, M., Warner G., Dunleavey, J., and Williamson, I. (2001a). Predictors of poor outcome and benefits from antibiotics in children with acute otitis media: pragmatic randomised trial. $B M J 325$, 22-26.

Little, P., Gould, C., Williamson, I., Moore, M., Warner, G., and Dunleavey, J. (2001b). Pragmatic randomised controlled trial of two prescribing strategies for childhood acute otitis media. BMJ 322 , 336-342.

Lopardo, G., Fridman, D., Gonzalez Arzac, M., Calmaggi, A. Smayevsky, J., Podesta, O., and Clara, L. (2007). Uropathogen resistance: are laboratory-generated data reliable enough? J. Chemother. 19, 33-37.

Lutters, M., and Vogt-Ferrier, N. B. (2008). Antibiotic duration for treating uncomplicated, symptomatic lower urinary tract infections in elderly women. Cochrane Database Syst. Rev. 3, CD001535.

Mandell, L. A., Wunderink, R. G., Anzueto, A., Bartlett, J. G., Campbell, G. D., Dean, N. C., Dowell, S. F., File, T. M., Musher, D. M., Niederman, M. S., Torres, A., and Whitney, C. G. (2007). Infectious Diseases Society of America/American Thoracic Society consensus guidelines on the management of comunity-acquired pneumonia in adults. Clin. Infect. Dis. 44(Suppl. 2), S27-S72.

Mazur, D., Schug, B. S., Evers, G., Larsimont, V., Fieger-Büschges, H. Gimbel, W., Keilbach-Bermann, A., and Blume, H. H. (1999). Bioavailability and selected pharmacokinetic parameters of clindamycin hydrochloride after administration of a new $600 \mathrm{mg}$ tablet formulation. Int. J. Clin. Pharmacol. Ther. 37, 386-392.

Mazzei, T., Novelli, A., and Arrigucci, S. (2009). Pharmacodynamic and pharmacokinetic of antibiotics for treatment of skin and soft tissue infections. Infez. Med. 17(Suppl. 4), 37-57.
Menéndez, R., Torres, A., Capelastegui, A., Prat, C., Rodríguez De Castro, F., and S.E.N.C.T. (2010). Community-acquired pneumonia. New guidelines of the Spanish Society of Pulmonary and Thoracic Surgery (SEPAR). Arch. Bronconeumol. 46, 543-558.

Mills, G. D., Oehley, M. R., and Arrol, B. (2005). Effectiveness of blactam antibiotics compared with antibiotics active against atypical pathogens in nonsevere community acquired pneumonia: meta-analysis. BMJ 330, 456-460.

Miyashita, N., Matsushima, T., and Oka, M. (2006). Guidelines for the management of communityacquired pneumonia in adults: an update and new recommendations. Intern. Med. 45, 419-428.

Mouton, J. W., Ambrose, P. G., Canton, R., Drusano, G. L., Harbarth, S., Macgowan, A., Theuretzbacher, U., and Turnidge, J. (2011). Conserving antibiotics for the future: new ways to use old and new drugs from a pharmacokinetic and pharmacodynamic perspective. Drug Resist. Updat. 14, 107-117.

Newton, P. N., Fernández, F. M., Green, M. D., Primo-Carpenter, J., and White, N. J. (2010). "Counterfeit and substandard anti-infectives in developing countries," in Antimicrobial Resistance in Developing Countries, eds A. Sosa, D. K. Byarugada, C. F. Amábile-Cuevas, I. Okeke, S. Kariuki, and P. R. Hsueh (New York: Springer), 413-443.

Nicolle, L., Bradley, S., Colgan, R., Rice, J., Schaeffer, A., and Hooton, T. M. (2005). Infectious Diseases Society of America guidelines for the diagnosis and treatment of asymptomatic bacteriuria in adults. Clin. Infect. Dis. 40, 643-654.

NIHCE. (2008). Prescribing of Antibiotics for Self Limiting Respiratory Tract Infections in Adults and Children in Primary Care (Clinical Guideline 69). Available at: www.nice.org.uk/CG69

O'Brien, T. F., and Stelling, J. M. (2007). "Monitoring antimicrobial resistance," in Antimicrobial Resistance in Bacteria, ed. C. F. AmábileCuevas (Wymondham, UK: Horizon Bioscience), 123-148.

Puhan, M. A., Vollenweider, D., Latshang, T., Steurer, J., and SteurerStey, C. (2007). Exacerbations of chronic obstructive pulmonary disease: when are antibiotics indicated? A systematic review. Respir. Res. 8, 30.

Rochon, P. A., Gurwitz, J. H., Cheung, C. M., Hayes, J. A., and Chalmers, T. C. (1994). Evaluating the quality 
of articles published in journal supplements compared with the quality of those published in the parent journal. JAMA 272, 108-113.

Ruhe, J. J., Smith, N., Bradsher, R. W., and Menon, A. (2007). Communityonset methicillin resistant Staphylococcus aureus skin and soft-tissue infections: impact of antimicrobia therapy on outcome. Clin. Infect. Dis. 44, 777-784.

Shefet, D., Robenshtok, E., Paul, M., and Leibovici, L. (2005). Empirical atypical coverage for inpatients with communityacquired pneumonia: systematic review of randomized controlled trials. Arch. Intern. Med. 165, 1992-2000.

Sirinavin, S., and Garner, P. (2000). Antibiotics for treating salmonella gut infections. Cochrane Database Syst. Rev. 2, CD001167.

Spurling, G. K., Del Mar, C. B., Dooley, L., and Foxlee, R. (2007). Delayed antibiotics for respiratory infections. Cochrane Database Syst. Rev. 3, CD004417.
Tambyah, P. A., and Maki, D. (2000). Catheter associated infection is rarely symptomatic: a prospective study of 1497 catheterized patients. Arch. Intern. Med. 160, 678-682.

Tenover, F. C., Mohammed, M. J., Stelling, J., O’Brien, T., and Williams, R. (2001). Ability of laboratories to detect emerging antimicrobial resistance: proficiency testing and quality control results from the Word Health Organization's external quality assurance system for antimicrobial susceptibility testing. J. Clin. Microbiol. 39, 241-250.

Vergison, A., Dagan, R., Arguedas, A., Bonhoeffer, J., Cohen, R., Dhooge, I., Hoberman, A., Liese, J., Marchisio, P., Palmu, A. A., Ray, G. T., Sanders, E. A. M., Simões, E. A. F., Uhari, M., Van Eldere, J., and Pelton, S. I. (2010). Otitis media and its consequences: beyond the earache. Lancet. Infect. Dis. 10, 195-203.

Vesga, O., Agudelo, M., Salazar, B. E., Rodriguez, C. A., and
Zuluaga, A. F. (2010). Generic vancomycin products fail in vivo despite being pharmaceutical equivalents of the innovator. Antimicrob. Agents Chemother. 54, 3271-3279.

Vogel, T., Verreault, R., Gourdeau, M., Morin, M., Grenier-Gosselin, L. and Rochette, L. (2004). Optimal duration of antibiotic therapy for uncomplicated urinary tractinfection in older women: a double-blind randomized controlled trial. CMAJ 170, 469-473.

WHO Department of Communicable Disease Surveillance and Response. (2001). WHO Global Strategy for Containment of Antimicrobial Resistance. Available at: http://www. who.int/csr/resources/publications/ drugresist/en/EGlobal_Strat.pdf

Conflict of Interest Statement: The authors declare that the research was conducted in the absence of any commercial or financial relationships that could be construed as a potential conflict of interest.
Received: 25 August 2011; accepted: 29 October 2011; published online: 24 November 2011.

Citation: Levy-Hara G, Amábile-Cuevas CF, Gould I, Hutchinson J, Abbo L, Saxynger L, Vlieghe E, Cardoso FLL, Methar S, Kanj S, Ohmagari $N$, Harbarth $S$ and ISC-ASW Group (2011) "Ten commandments" for the appropriate use of antibiotics by the practicing physician in an outpatient setting. Front. Microbio. 2:230. doi: 10.3389/fmicb.2011.00230

This article was submitted to Frontiers in Antimicrobials, Resistance and Chemotherapy, a specialty of Frontiers in Microbiology.

Copyright (C) 2011 Levy-Hara, AmábileCuevas, Gould, Hutchinson, Abbo, Saxynger, Vlieghe, Cardoso, Methar, Kanj, Ohmagari, Harbarth and ISCASW Group. This is an open-access article subject to a non-exclusive license between the authors and Frontiers Media $S A$, which permits use, distribution and reproduction in other forums, provided the original authors and source are credited and other Frontiers conditions are complied with. 